\title{
Isolated Chemotherapeutic Perfusion
}

National Cancer Institute

\section{Source}

National Cancer Institute. Isolated Chemotherapeutic Perfusion. NCI Thesaurus. Code C15296.

The delivery of chemotherapy to a specific tissue area that is excluded from the general circulation during the period of infusion, which allows for a high concentration of the drug in the tumour area as well as sparing of the rest of the body from the side effects of the drug. 